\title{
Where the Future Goes: What do we Need to Know in the ARDS and how Lung Imaging Can Deal with this?
}

\author{
Jean-Christophe Richard ${ }^{1,2}$, Céline Pouzot ${ }^{2,3}$ and Claude Guerin ${ }^{*}, 1,2$
}

\author{
${ }^{I}$ Hospices Civils de Lyon, Service de Réanimation Médicale et d'Assistance Respiratoire, Hôpital de la Croix Rousse; \\ Université de Lyon, Université Lyon 1, Lyon, France \\ ${ }^{2}$ CREATIS (CNRS UMR 5515 et INSERM Unité 630), Lyon, France \\ ${ }^{3}$ Service de Soins Intensifs Animaux et Medecine d'Urgence, Ecole Nationale Vétérinaire de Lyon, Marcy l'etoile, \\ France
}

\begin{abstract}
Acute respiratory distress syndrome (ARDS) remains a clinical challenge for intensivists, despite extensive experimental and clinical research over the past thirty years. Meanwhile, lung imaging techniques have emerged as invaluable non-invasive tools and have considerably modified and improved management of many lung pathologies. The purpose of this review is to list major unanswered questions in ARDS and to speculate on how lung imaging may provide answers in the near future.
\end{abstract}

Keywords: ARDS, positron emission tomography, electrical impedance tomography, computed tomography, SPECT.

\section{INTRODUCTION}

Since its first description in 1967 by Ashbaugh [1], the acute respiratory distress syndrome (ARDS) remains a clinical challenge for physicians. Mortality of this syndrome remains unacceptably high around $40 \%$, and is stable over time despite extensive experimental and clinical research [2]. A lot of questions remain unsolved, whether related to physiopathology, prognosis or appropriate treatment of this syndrome. The reasons for which ARDS remains a particularly difficult disease for both researchers and clinicians are numerous. First, physiopathology of lung injury is incredibly complex, and further complexified by the wide spectrum of clinical conditions leading to this syndrome [3]. Second, lung lesions are evolving over time, in several often overlapping stages, with different clinical, histopathological, and radiographic manifestations [3]. Third, there is an extreme spatial heterogeneity of lung lesions during ARDS, making both global and regional physiologic measurements unrepresentative of the complexity of lung injury. Finally, the physiopathology of ARDS is intrinsically related to mechanical ventilation, which may interfere with the evolution of the syndrome. Lung imaging techniques are attractive to study ARDS because of their non-invasiveness allowing repetitive studies over time, their ability to provide both regional and global measurements, and their potential to give both morphologic and functional information on lung status. The purpose of this review is to list major unanswered questions in ARDS and to speculate on how lung imaging might provide answers.

*Address correspondence to this author at the Service de Réanimation Médicale et d'Assistance Respiratoire, 103 Grande Rue de la Croix Rousse, 69004 Lyon, France; Tel: (+33) 4720717 62; Fax: (+33) 4720717 74;

E-mail: claude.guerin@chu-lyon.fr

\section{IS MY PATIENT REALLY SUFFERING FROM ARDS?}

Improving diagnosis of ARDS is of paramount importance, in order to better select appropriate therapy for patients (i.e. decreasing tidal volume, increasing positive end-expiratory pressure (PEEP),...). To date, several studies have shown that sensitivity and specificity of the current definition of ARDS [4] approximate 80\% [5]. A new definition has been proposed, based on the Delphi technique, but mildly increased specificity, at the price of a significant decrease in sensitivity [6]. One of the reasons for the poor performance of ARDS current definition may be that neither pulmonary vascular permeability nor lung inflammation, two landmark features of ARDS, are part of ARDS criteria. Another problem is that, to date, the only gold standard for ARDS diagnosis is based on the pathological finding of diffuse alveolar damage, whose relevance as gold standard may be questionable since this pattern may be observed in several other diseases (such as drug toxicity, fibrosis, collagen vascular disease..) [7], and requires open lung biopsy, an invasive procedure which cannot be done in any unselected ARDS patient. Furthermore, bedside chest radiography, one of the 4 diagnosis criteria of current ARDS definition, has been shown poorly reliable in ARDS, with a diagnosis accuracy of $70 \%$, as compared to computed tomography (CT) [8]. Finally, a bio-marker specific for ARDS would be the ultimate goal for reliable diagnosis of this syndrome, but extensive search has been to date unsuccessful, probably because of the great variety of etiologies leading to acute lung injury. There is thus an urgent need for new non-invasive diagnostic tools for ARDS, and lung imaging is a credible candidate for this purpose in the near future. High resolution morphological imaging such as lung CT may be used as a screening tool for ARDS diagnosis, particularly if bedside devices become widely available [9]. However, while CT may already give 
functional information on vascular permeability [10], at the price of increased radiation exposure related to dynamic acquisition, the probability is scarce that this technique will ever allow measurement of lung inflammation in the future. Nuclear Medicine techniques might be the best tool for ARDS diagnosis, but a combination of tracers should be required. Indeed, increased permeability is not a specific feature of ARDS and has been described in hydrostatic pulmonary edema, in relation with increased convective protein transport across the pulmonary endothelium [11]. It is then likely that combined measurements of lung vascular permeability, inflammation and morphological information are required. In this connection, wide diffusion of single photon emission computed tomography (SPECT)/CT device would help the development of this new tool, since simultaneous dual isotope imaging is a unique feature of SPECT. Improving ARDS diagnosis with imaging may help to homogenize population of patients included in future clinical trials and increase the ability to detect significant differences between treatments. This technique may also help to differentiate ARDS from other conditions, since a great variety of diseases may fulfill the criteria of current ARDS definition [12-14].

\section{WILL MY PATIENT AT-RISK, WHO IS AT RISK FOR ARDS, SUBSEQUENTLY DECLARE ARDS?}

There is a wide variety of clinical disorders associated with subsequent development of ARDS, but only a small proportion of at risk-patients will ultimately develop this syndrome [3]. Early identification of these patients may be of paramount importance should new therapies be developed to prevent this disorder. In this connection, starting lung protective mechanical ventilation strategies before ARDS onset is one option among others. Because of its noninvasiveness, lung imaging is an attractive tool in this setting. It should be stressed that patient transport to imaging facility is certainly safer before ARDS onset than once ARDS is fully established PET imaging is already being proposed for that purpose, since $\left[{ }^{18} \mathrm{~F}\right]$-fluorodeoxyglucose ( $\left.\left[{ }^{18} \mathrm{~F}\right]-\mathrm{FDG}\right)$ uptake has been shown to increase significantly in patients with pulmonary contusion who subsequently develop ARDS, contrary to patients with favorable evolution [15]. This preliminary study needs to be confirmed, but favors future works in this direction. Nuclear Medicine imaging techniques are clearly the most likely candidates for this purpose, since functional changes precede morphological changes and may even be the earliest marker for the evolution towards ARDS.

\section{HOW CAN I ASSESS THE SEVERITY OF MY ARDS PATIENT AT ADMISSION?}

Risk stratification in ARDS is crucial in order to design randomized controlled trials with homogeneous response to the tested intervention. Results of recent clinical trials suggest that response to ARDS therapies may indeed depend on the severity of underlying lung injury [16, 17]. For example, post-hoc analysis of the Express trial [16] has shown that high PEEP was associated with a decreased mortality in the most hypoxemic patients, and with an increased mortality in those patients with acute lung injury (a mild form of lung injury sharing identical criteria with ARDS except for $\mathrm{PaO}_{2} / \mathrm{FiO}_{2}$ ratio below $300 \mathrm{mmHg}$ instead of $200 \mathrm{mmHg}$ in ARDS [4]). However, $\mathrm{PaO}_{2} / \mathrm{FiO}_{2}$ ratio alone is an unreliable parameter for risk stratification [18], mainly since it can be manipulated by modifying PEEP or $\mathrm{FiO}_{2}$ among other variables [19]. Identification of patients with a high-risk of death may be performed by using standardized ventilatory settings during the first 24 hours after ARDS onset [19], but delayed inclusion may jeopardize the tested treatment and impede development of aggressive early therapies that have been shown beneficial in sepsis [20]. Lung imaging has already been shown efficient for risk stratification. Indeed, Gattinoni's group has shown that the percentage of potentially recruitable lung assessed with CT (defined as the proportion of lung tissue in which aeration was restored at airway pressures between 5 and $45 \mathrm{~cm}$ of water) was an independent risk factor for death in ARDS [21]. In this study, mortality increased from $15 \%$ to $41 \%$ between the quartile of patients with the fewer amount and the quartile with the greatest amount of potentially recruitable lung tissue. However, translation of this technique in the clinical setting is hardly conceivable, considering the requirement of time and resource consuming quantitative image analysis, and requirement for patient transport to imaging facility that would leave the most severe patients beyond the scope of this method. Electrical impedance tomography (EIT) is an attractive alternative to $\mathrm{CT}$ to assess lung recruitability [22]. It may be performed at the bedside, and is a strong candidate to help risk stratification in ARDS patients, based on the methodology developed by Gattinoni [21]. Lung ultrasonography is another technique with potential to assess non-invasively lung recruitment at the bedside [23], but its ability to give quantitative and not only semi-quantitative results remains to be proven. Finally, assessing lung permeability with portable $\gamma$-camera scintigraphy as a surrogate for severity of lung injury may be another way for risk stratification in ARDS, but preliminary results were disappointing [11].

\section{IS MY ARDS PATIENT VENTILATED WITH SAFE SETTINGS?}

Since high tidal volumes have been shown to increase ARDS mortality in a large randomized controlled trial [24], avoiding ventilator-induced lung injury (VILI) is one of the main concerns when ventilating ARDS patients. Despite initial controversies, setting the ventilator with a low tidal volume of $6 \mathrm{ml} / \mathrm{kg}$ of predicted body weight and targeting a plateau pressure of the respiratory system below $30 \mathrm{cmH}_{2} \mathrm{O}$ has become a standard of care in ARDS treatment. However, approximately $30 \%$ of ARDS patients ventilated with these ventilatory settings still exhibit lung hyperinflation and excessive lung inflammation [25], favoring further reduction in tidal volume to avoid volotrauma (VILI secondary to excessive lung strain). Repetitive recruitment-derecruitment is another mechanism suspected to be involved in VILI [26], and may be prevented by optimizing PEEP level. However, setting the right PEEP remains a matter of intense debate, and disappointing results came from recent large randomized controlled trials comparing two PEEP levels irrespective of patient lung characteristics [16, 27, 28].

Tailoring tidal volume to effective aerated volume in ARDS (so called "baby lung") to avoid lung hyperinflation and PEEP level to avoid repetitive lung recruitmentderecruitment may be a solution, since lung aeration and respiratory mechanics are highly heterogeneous between ARDS patients. Computed tomography is a reliable tool to 
assess both lung tidal hyperinflation and repetitive recruitment-derecruitment in clinical research studies, but requires patient transport, radiation exposure, and would require repetitive measurements over time [25] after each ventilatory adjustment. EIT may be an attractive alternative approach, with potential for repetitive measurements at the bedside, using mathematical modeling of regional impedance vs time curves [29]. However clinical validation of this methodology remains to be performed since several technical limitations may impair relevance of such measurements (low spatial resolution, acquisition limited to a small part of the lung, intensity of impedance signal not limited to lung aeration, among others). Nevertheless, with EIT or another emerging new technique available at the bedside, imaging-assisted mechanical ventilation may well become a major advance in mechanical ventilation in the near future.

\section{WHAT IS THE PHYSIOPATHOLOGY OF GAS EXCHANGE IN MY ARDS PATIENT?}

Most of ARDS ventilatory treatments (PEEP, recruitment maneuvers, prone position,...) have not only an effect on lung ventilation and aeration, but also on lung perfusion [3032]. Some pharmacological agents frequently used in ARDS (nitric oxide [33], almitrine [34], recombinant human activated $C$ protein [35], among others) also act on the lung perfusion and may interact negatively with treatments that act on the lung ventilation. Therefore, evaluation of ventilation-perfusion relationships is of paramount importance, when evaluating response to such therapies. For example, Musch et al. have shown using PET, that adverse response to recruitment maneuver may be explained by redistribution of pulmonary blood flow toward less-aerated dependent regions increasing shunt and altering gas exchange [36]. PET imaging is certainly the gold standard to study ventilation-perfusion relationships, but will probably be confined as a research tool considering the complexity and cost of such measurements. CT has an established potential to assess both lung perfusion (using contrast agent and modeling of their kinetics in the lung [37, 38]), and ventilation using inhaled Xenon and mathematical modeling of gas washout from the lung [39]. However, dynamic acquisition is required for mathematical modeling and hence increase radiation exposure. Furthermore, inhalation of hypoxic gas and transport requirement to imaging facility preclude application of this method in the most severe patients. Magnetic resonance imaging has also a confirmed potential for assessing both ventilation and perfusion [4042]. However, technique complexity, restricted access and transport requirement are major limitations in ARDS. Finally, EIT may again find a place in the clinical setting for that purpose, since variations of thoracic impedance are related to both lung aeration (and hence ventilation) and blood volume (and hence, lung regional stroke volume) [43, 44], but this technique is still in its early stage of development.

\section{WHICH STRATEGY SHOULD I ADOPT IN PATIENTS WITH PERSISTENT ARDS?}

ARDS patients who fail to improve respiratory function by day seven are deemed to present persistent or unresolving ARDS, characterized by persistent elevation in circulating and pulmonary levels of inflammatory cytokines and chemokines, elevated markers of alveolo-capillary membrane permeability and lung fibroproliferation. Mortality of this syndrome was considered in excess of $80 \%$, based on studies performed in the 1980s [45-47], but may be lower $(30-50 \%)$ on the basis of more recent studies [14, 48]. Randomized controlled trials using steroids to counteract pulmonary fibroproliferation gave conflicting results [48, 49], and, to date, there is no established treatment of persistent ARDS. One of the reasons explaining these disappointing results is that physiopathology of this syndrome is highly heterogeneous. Systematic open lung biopsies have indeed found evidence for fibroproliferation in less than $50 \%$ of patients, infection in approximately $60 \%$ of patients, and miscellaneous diagnosis erroneously taken for ARDS in more than $10 \%$ of patients [14]. New developments in lung imaging could help selecting patients for inclusion in clinical trials focusing on treating fibroproliferation, help for differential diagnosis of ARDS, or possibly help selecting lung region to improve lung biopsy yield. Computed tomography may help the diagnosis of established fibrosis [50], but is usually useless at the early phases of fibroproliferation. Isotopic functional imaging may be of interest in this setting, should specific tracers for fibroproliferation and infection were to be developed. To date, collagen synthesis and extracellular matrix degradation may be tracked by PET using ${ }^{18} \mathrm{~F}$-labeled proline analogs [51], and ${ }^{18}$ F-labelled metalloproteinase inhibitors [52, 53], respectively. SPECT imaging may also be of interest, by targeting somatostatin receptor subtype 2 expressed on activated fibroblast with ${ }^{111}$ In-octreotide, a synthetic somatostatin analog with strong affinity for this receptor [54]. However, none of the preceding tracers have been tested in persistent ARDS.

\section{CONCLUSION}

Many unanswered questions in ARDS might be solved by lung imaging. EIT may be the technique of choice for risk stratification in ARDS, and to help managing ventilatory settings at the bedside, unless low spatial resolution and limited field of view restricted to a small part of the lung impair relevance of regional lung measurements obtained with this technique. Nuclear medicine techniques should help to identify at-risk patient before ARDS onset, to define subgroups of ARDS patients sharing similar physiopathology, to exclude other diagnosis than ARDS, and to early identify lung fibroproliferation. However, translation of these techniques to patient care may be hindered by requirement of patient transport to imaging facilities. Developing new imaging devices with availability at the bedside would thus be of paramount importance to improve management of ARDS patients in the future.

\section{REFERENCES}

[1] Ashbaugh DG, Bigelow DB, Petty TL, Levine BE. Acute respiratory distress in adults. Lancet 1967; 2: 319-23.

[2] Phua J, Badia JR, Adhikari NK, et al. Has mortality from acute respiratory distress syndrome decreased over time?: A systematic review. Am J Respir Crit Care Med 2009; 179: 220-7.

[3] Ware LB, Matthay MA. The acute respiratory distress syndrome. N Engl J Med 2000; 342: 1334-49.

[4] Bernard GR, Artigas A, Brigham KL, et al. Report of the American-European consensus conference on ARDS: definitions, mechanisms, relevant outcomes and clinical trial coordination. The Consensus Committee. Intensive Care Med 1994; 20: 225-32. 
[5] Esteban A, Fernandez-Segoviano $\mathrm{P}$, Frutos-Vivar F, et al. Comparison of clinical criteria for the acute respiratory distress syndrome with autopsy findings. Ann Intern Med 2004; 141: 4405 .

[6] Ferguson ND, Frutos-Vivar F, Esteban A, et al. Acute respiratory distress syndrome: underrecognition by clinicians and diagnostic accuracy of three clinical definitions. Crit Care Med 2005; 33: 2228-34.

[7] American Thoracic Society/European Respiratory Society International Multidisciplinary Consensus Classification of the Idiopathic Interstitial Pneumonias. This joint statement of the American Thoracic Society (ATS), and the European Respiratory Society (ERS) was adopted by the ATS board of directors, June 2001 and by the ERS Executive Committee, June 2001. Am J Respir Crit Care Med 2002; 165: 277-304.

[8] Lichtenstein D, Goldstein I, Mourgeon E, Cluzel P, Grenier P, Rouby JJ. Comparative diagnostic performances of auscultation, chest radiography, and lung ultrasonography in acute respiratory distress syndrome. Anesthesiology 2004; 100: 9-15.

[9] McCunn M, Mirvis S, Reynolds N, Cottingham C. Physician utilization of a portable computed tomography scanner in the intensive care unit. Crit Care Med 2000; 28: 3808-13.

[10] Schueller-Weidekamm C, Wassermann E, Redl H, et al. Dynamic CT measurement of pulmonary enhancement in piglets with experimental acute respiratory distress syndrome. Radiology 2006; 239: 398-405

[11] Schuster DP, Stark T, Stephenson J, Royal H. Detecting lung injury in patients with pulmonary edema. Intensive Care Med 2002; 28 : 1246-53.

[12] Patel SR, Karmpaliotis D, Ayas NT, et al. The role of open-lung biopsy in ARDS. Chest 2004; 125: 197-202.

[13] Schwarz MI, Albert RK. "Imitators" of the ARDS: implications for diagnosis and treatment. Chest 2004; 125: 1530-5.

[14] Papazian L, Doddoli C, Chetaille B, et al. A contributive result of open-lung biopsy improves survival in acute respiratory distress syndrome patients. Crit Care Med 2007; 35: 755-62.

[15] Rodrigues RS, Miller PR, Bozza FA, et al. FDG-PET in patients at risk for acute respiratory distress syndrome: a preliminary report. Intensive Care Med 2008; 34: 2273-8.

[16] Mercat A, Richard JC, Vielle B, et al. Positive end-expiratory pressure setting in adults with acute lung injury and acute respiratory distress syndrome: a randomized controlled trial. JAMA 2008; 299: 646-55.

[17] Taccone P, Pesenti A, Latini R, et al. Prone positioning in patients with moderate and severe acute respiratory distress syndrome: a randomized controlled trial. JAMA 2009; 302: 1977-84.

[18] Rubenfeld GD, Herridge MS. Epidemiology and outcomes of acute lung injury. Chest 2007; 131: 554-62.

[19] Villar J, Perez-Mendez L, Lopez J, et al. An early PEEP/FIO2 trial identifies different degrees of lung injury in patients with acute respiratory distress syndrome. Am J Respir Crit Care Med 2007; 176: 795-804.

[20] Rivers E, Nguyen B, Havstad S, et al. Early goal-directed therapy in the treatment of severe sepsis and septic shock. N Engl J Med 2001; 345: 1368-77.

[21] Gattinoni L, Caironi P, Cressoni M, et al. Lung recruitment in patients with the acute respiratory distress syndrome. N Engl J Med 2006; 354: 1775-86

[22] Meier T, Luepschen H, Karsten J, et al. Assessment of regional lung recruitment and derecruitment during a PEEP trial based on electrical impedance tomography. Intensive Care Med 2008; 34(3): 543-50.

[23] Gardelli G, Feletti F, Gamberini E, Bonarelli S, Nanni A, Mughetti M. Using sonography to assess lung recruitment in patients with acute respiratory distress syndrome. Emerg Radiol 2009; 16: 21921.

[24] Ventilation with lower tidal volumes as compared with traditional tidal volumes for acute lung injury and the acute respiratory distress syndrome. N Engl J Med 2000; 342: 1301-8.

[25] Terragni PP, Rosboch G, Tealdi A, et al. Tidal hyperinflation during low tidal volume ventilation in acute respiratory distress syndrome. Am J Respir Crit Care Med 2007; 175: 160-6.

[26] Muscedere JG, Mullen JB, Gan K, Slutsky AS. Tidal ventilation at low airway pressures can augment lung injury. Am J Respir Crit Care Med 1994; 149: 1327-34.
[27] Brower RG, Lanken PN, MacIntyre N, et al. Higher versus lower positive end-expiratory pressures in patients with the acute respiratory distress syndrome. N Engl J Med 2004; 351: 327-36.

[28] Meade MO, Cook DJ, Guyatt GH, et al. Ventilation strategy using low tidal volumes, recruitment maneuvers, and high positive endexpiratory pressure for acute lung injury and acute respiratory distress syndrome: a randomized controlled trial. JAMA 2008; 299: 637-45.

[29] Grant CA, Fraser JF, Dunster KR, Schibler A. The assessment of regional lung mechanics with electrical impedance tomography: a pilot study during recruitment manoeuvres. Intensive Care Med 2009; 35: 166-70.

[30] Schuster DP, Haller J. Effects of body position on regional pulmonary blood flow during acute pulmonary edema in dogs : a positron emission tomography study. J Crit Care 1991; 6: 19-28.

[31] Schuster DP, Howard DK. The effect of positive end-expiratory pressure on regional pulmonary perfusion during acute lung injury. J Crit Care 1994; 9: 100-10.

[32] Richard JC, Bregeon F, Costes N, et al. Effects of prone position and positive end-expiratory pressure on lung perfusion and ventilation. Crit Care Med 2008; 36: 2373-80.

[33] Gust R, McCarthy TJ, Kozlowski J, Stephenson AH, Schuster DP. Response to inhaled nitric oxide in acute lung injury depends on distribution of pulmonary blood flow prior to its administration. Am J Respir Crit Care Med 1999; 159: 563-70.

[34] Richard JC, Janier M, Lavenne F, et al. Effect of position, nitric oxide, and almitrine on lung perfusion in a porcine model of acute lung injury. J Appl Physiol 2002; 93: 2181-91.

[35] Richard JC, Bregeon F, Leray V, et al. Effect of activated protein C on pulmonary blood flow and cytokine production in experimental acute lung injury. Intensive Care Med 2007; 33: 2199-206.

[36] Musch G, Harris RS, Vidal Melo MF, et al. Mechanism by which a sustained inflation can worsen oxygenation in acute lung injury. Anesthesiology 2004; 100: 323-30.

[37] Chon D, Beck KC, Larsen RL, Shikata H, Hoffman EA. Regional pulmonary blood flow in dogs by 4D-X-ray CT. J Appl Physiol 2006; 101: 1451-65.

[38] Wu X, Latson LA, Wang T, Driscoll DJ, Ensing GJ, Ritman EL. Regional pulmonary perfusion estimated by high-speed volume scanning CT. Am J Physiol Imaging 1988; 3: 73-80.

[39] Simon BA. Non-invasive imaging of regional lung function using X-ray computed tomography. J Clin Monit Comput 2000; 16: 43342 .

[40] Edelman RR, Hatabu H, Tadamura E, Li W, Prasad PV. Non invasive assessment of regional ventilation in the human lung using oxygen-enhanced magnetic resonance imaging. Nat Med 1996; 2: 1236-9.

[41] Hatabu H, Tadamura E, Levin DL, et al. Quantitative assessment of pulmonary perfusion with dynamic contrast-enhanced MRI. Magn Reson Med 1999; 42: 1033-8.

[42] Rizi RR, Baumgardner JE, Ishii M, et al. Determination of regional VA/Q by hyperpolarized 3He MRI. Magn Reson Med 2004; 52 : 65-72.

[43] Fagerberg A, Stenqvist O, Aneman A. Electrical impedance tomography applied to assess matching of pulmonary ventilation and perfusion in a porcine experimental model. Crit Care 2009; 13 : R34.

[44] Frerichs I, Pulletz S, Elke G, et al. Assessment of changes in distribution of lung perfusion by electrical impedance tomography. Respiration 2009; 77: 282-91.

[45] Bernard GR, Luce JM, Sprung CL, et al. High-dose corticosteroids in patients with the adult respiratory distress syndrome. N Engl J Med 1987; 317: 1565-70.

[46] Bone RC, Maunder R, Slotman G, et al. An early test of survival in patients with the adult respiratory distress syndrome. The $\mathrm{PaO} 2 / \mathrm{FIo} 2$ ratio and its differential response to conventional therapy. Prostaglandin E1 Study Group. Chest 1989; 96: 849-51.

[47] Meduri GU. Host defense response and outcome in ARDS. Chest 1997; 112: 1154-8.

[48] Steinberg KP, Hudson LD, Goodman RB, et al. Efficacy and safety of corticosteroids for persistent acute respiratory distress syndrome. N Engl J Med 2006; 354: 1671-84.

[49] Meduri GU, Headley AS, Golden E, et al. Effect of prolonged methylprednisolone therapy in unresolving acute respiratory distress syndrome: a randomized controlled trial. JAMA 1998; 280: $159-65$. 
[50] Howling SJ, Evans TW, Hansell DM. The significance of bronchial dilatation on $\mathrm{CT}$ in patients with adult respiratory distress syndrome. Clin Radiol 1998; 53: 105-9.

[51] Wallace WE, Gupta NC, Hubbs AF, et al. Cis-4- $\left[{ }^{(18)}\right.$ F]fluoro-Lproline PET imaging of pulmonary fibrosis in a rabbit model. $\mathrm{J}$ Nucl Med 2002; 43: 413-20.

[52] Breyholz HJ, Wagner S, Levkau B, Schober O, Schafers M, Kopka K. A ${ }^{18}$ F-radiolabeled analogue of CGS $27023 \mathrm{~A}$ as a potential agent for assessment of matrix-metalloproteinase activity in vivo. Q J Nucl Med Mol Imaging 2007; 51: 24-32.

[53] Wagner S, Breyholz HJ, Holtke C, et al. A new ${ }^{18}$ F-labelled derivative of the MMP inhibitor CGS 27023A for PET: radiosynthesis and initial small-animal PET studies. Appl Radiat Isot 2009; 67: 606-10.

[54] Lebtahi R, Moreau S, Marchand-Adam S, et al. Increased uptake of 111In-octreotide in idiopathic pulmonary fibrosis. J Nucl Med 2006; 47: 1281-7.

Received: December 9, 2009

Revised: January 12, 2010

Accepted: January 12, 2010

(C) Richard et al.; Licensee Bentham Open.

This is an open access article licensed under the terms of the Creative Commons Attribution Non-Commercial License (http: //creativecommons.org/licenses/by-nc/

$3.0 /$ ) which permits unrestricted, non-commercial use, distribution and reproduction in any medium, provided the work is properly cited. 